\title{
THE ELEVATED TEMPERATURE COMPRESSIVE RESPONSE OF NOTCHED COMPOSITE LAMINATES
}

\author{
Junghyun Ahn and Anthony M. Waas ${ }^{\dagger}$ \\ Composite Structures Laboratory \\ Department of Aerospace Engineering, University of Michigan, Ann Arbor, MI 48109-2118
}

February 1, 1999

\begin{abstract}
A compression test at elevated temperature was performed to investigate the notch sensitivity and failure mechanisms of fibrous laminated composite plates containing a stress raiser, in the form of a circular cutout, under equi-biaxial and uniaxial compressive loading. Strains measured at various locations on the specimen surface and cutout edge were used to monitor the initiation of failure. Unloading the specimen before global failure made it possible to understand the failure mechanism associated with the final failure mode.
\end{abstract}

\section{Introduction}

For structural applications, polymer based fibrous composite materials possess several favorable attributes when compared to other traditional materials such as metals. A high specific stiffness is one attribute that favors applications in the aerospace industry. Because of their complex microstructure, these materials exhibit a variety of failure mechanisms when subjected to mechanical and thermal loads. Understanding these mechanisms and developing micromechanics based modeling capability have been subject areas that have received a considerable amount of attention in the recent past. In the present paper, we report the results of an experimental investigation into the failure mechanisms in fibrous composite laminated plates. Plates containing a centrally located circular hole were subjected to planar compressive loads, both biaxial and uniaxial, under room $\left(25^{\circ}\right.$ C) and elevated temperature $\left(200^{\circ} \mathrm{C}\right)$. The motivation stemmed from a problem commonly occurring in aerospace applications where flat plates and panels containing cutouts have to be designed to carry a certain amount of mechanical load under various operational temperatures. An important question that arises in this process is the identification of the dominant failure mechanism at a given temperature and loading condition, which is activated during service conditions. A secondary, but equally important question is the amount of stiffness and strength degradation in terms of the failure initiation in the presence of an elevated temperature environment.

In section 2, we present details of the experiment, the specimens and the test procedure. Next, we summarize and tabulate the results obtained from the different types of laminates, with important observations deduced from the tests to ascertain the laminate stiffness properties as well as a discussion of the effect of the environment on the observed failure mode. Finally, we remark on how the failure characteristics are related to the lay-up and environment.

\section{Experimental Method}

\subsection{Test Specimens}

As pointed out in several papers (See Khamseh \& Waas, 1997), difficulties associated with stress concentrations are encountered in the design of a cruciform shaped planar specimen for in-plane biaxial loading, in so far as achieving failure in the center of the specimen.

'Ph.D. Candidate, Department of Aerospace Engineering, University of Michigan, Ann Arbor, Member AIAA Copyright (C) 1999 by Junghyun Ahn, Published by the American Institute of Aeronautics and Astronautics, Inc. with permission.

${ }^{\dagger}$ Associate Professor of Aerospace Engineering, Associate Fellow, AIAA. 
In order to select the size of the specimen, we generated a model of the notched laminated plate and load introduction grips(steel) using the ABAQUS $^{\ddagger}$ FEA software package. The stress analysis program was used to examine the effect of several specimen geometries on the stress concentrations due to the applied loads. The loads were applied at the boundaries of the loading arms by use of displacement constraints. Eight noded parabolic plane stress elements were used to model the plate material and steel grips. Ply properties were entered from which ABAQUS calculates the equivalent plane stress constants using classical lamination theory. It was concluded from the results that a cruciform configuration matching the dimensions given in Figure 1, was the desirable specimen shape.

The word 'desirable' is used to refer to a stress state for which an in-plane region in the interior of the specimen (shown as the cross hatched area in Figure 2) is not influenced by the effects of the far field edges (i.e., edge curvatures identified as $R_{c}$ in Figure 1) of the plate due to the loading.

Specimen configurations corresponding to several values of $R_{c}$ were studied using the FEA prior to arriving at a 'optimum' value of $R_{\mathrm{c}}$ based on the condition that the specimen with a hole does not contain effects associated with the stress concentration at the hole interfering with nonuniformities in the stress field generated on account of the edge curvatures. For the composite plate we studied this 'working' area translated into a $6.35 \mathrm{~cm}$ (2.5 in.) square region in the middle of the cruciform configuration.

The test specimens were made of graphite / toughened epoxy material composed of Hercules IM7 (Intermediate Modulus) fiber and 977-3 toughened epoxy matrix, designed for operation at high temperatures. In Table 1, we show the lamina properties, based on data provided by the manufacturer. The stacking sequence for these symmetric laminates were as follows: Cross-Ply $[0 /+90]_{128}$ and Angle-Ply $[+60 /-60]_{12 s .}$. In Table 2, we have listed the laminate material properties, calculated using generalized classical lamination theory(CLT). The linear elastic plane stress solution that corresponds to the problem at hand, as given in Lekhnitskii (1968), was used to

\footnotetext{
${ }^{\ddagger}$ We are grateful to Hibbit, Carlson and Sorenson Inc. for making ABAQUS available under academic site license.
}

calculate the stress field corresponding to the uniaxial and equi-biaxial loading. The obtained solution was next verified with the strain data (farfield and near the hole edge)that was measured in the room temperature test for each laminate type. Such a check yielded good agreement between test data and the 2D-elasticity solution.

The inplane dimensions of the test specimens are given in Figure 1. The thickness of the laminates were $0.635 \mathrm{~cm}(0.25$ in.) with a 0.013 $\mathrm{cm}(0.005 \mathrm{in}$.) tolerance. In the center of the steel grips, a $0.724 \mathrm{~cm}(0.285$ in.) channel, $3.048 \mathrm{~cm}$ (1.200 in.) in depth, was machined along the length of the grip. A specimen arm sat in this channel, bonded to the walls of the channel with the use of Devcon $\AA$ brand plastic steel putty adhesive, treated with release agent in order to allow for ease of separation of the two materials at the end of an experiment. More importantly, the Devcon ${ }^{\circledR}$ putty acted as an interface between the specimen edge and the grip surface on which the specimen 'sat' effectively smoothening out the interface surface irregularities between the two materials and ensuring a smooth load transfer. To ensure proper alignment of the specimen inside the channel (i.e., ensuring reasonably centered seating of the specimen inside the channel), metal shim plates of various thickness were added to both sides of the specimen to eliminate any gap inside the channel.

\subsection{Loading apparatus}

The biaxial loading frame has four load actuators capable of exerting tensile / compressive loads of $222 \mathrm{kN}(50,000 \mathrm{lbf})$ when mated to a 20.7 MPa (3000 psi) hydraulic power supply. It should be noted than each of the actuators can be programmed to operate in a load or displacement feedback control mode (via the use of a load cell or displacement transducer) fully independent of the other three cylinders, thereby allowing for both uniaxial as well as biaxial tests. Two load cells were used in the system, one along each loading axis, each rated for a magnitude of $222 \mathrm{kN}$ $(50,000 \mathrm{lbf})$ in tension and compression.

\subsection{Radiation Heating Setup}

To perform a compression test at elevated temperature, a feedback controlled radiation heating element with an insulation tunnel (Figure 3) was designed and used. Special strain gages for high temperature (mounted with high temperature glue and lead wire insulated for 
thermal protection) were used for the test. To ensure a steady temperature in the enclosed test chamber, four locations in the test chamber were used to monitor temperature. In addition, thermocouple gages placed inside the specimen cutout edge and on the specimen surface was used to verify that the specimen temperature is fairly even (less than $2^{\circ} \mathrm{C}$ change from location to location). The load cell and the loading frame were cooled by circulating water through copper pipe wrapped around both parts. The maximum temperature of the tests was limited to $200^{\circ} \mathrm{C}$ $\left(392^{\circ} \mathrm{F}\right)$.

\subsection{Data Acquisition}

Surface strain measurements at various locations on the specimen were recorded with strain gages. Strain gages were mounted along the edges of the hole, as well as in the corresponding far field region. A set of two additional strain gages were mounted inside the hole, along the wall thickness, in order to record changes in strain in the out of plane(through the thickness)direction, revealing failure initiation. Strain gage readings, along with load cell readings were monitored via a custom data acquisition system.

\subsection{Test Procedure}

The 48 ply composites were tested under uniaxial and $1: 1$ (in far-field displacement) biaxial loading at both room temperature and $200^{\circ} \mathrm{C}$ in order to understand the failure mechanisms and how they are affected by temperature.

The catastrophic nature of failure in composites and the additional limitation placed upon the visual investigation of failure initiation and progression suggested a displacement controlled mode for the tests (as opposed to the load control). This facilitates examination of specimens loaded to initial (local) failure but recovered prior to global failure. In a displacement feedback control mode.

Each opposing pair of pistons was programmed to move a certain distance in a specified time interval. Preliminary results indicated that a rate of $0.381 \mathrm{~cm}(0.15 \mathrm{in}$.) in 25 minutes for piston travel would assure a quasistatic test. The influence of hole size on the failure mode had been established and verified before (Khamseh and Waas, 1992, 1997). Therefore, in the present study one hole size (0.5 in. Diameter) was chosen for all specimens.
Each test consists of loading a particular type of laminate until global failure to estimate the ultimate strength of the specimen. This information is used subsequently to aid in unloading specimens that have failure initiated but not reached their ultimate load carrying capacity. A sudden nonlinear (with respect to a far-field load component) increase in strain inside the hole (strain gage placed through the thickness on the hole edge) indicates that there is a failure initiation at the hole edge of the specimen, even though there may not be a sign of global failure of the specimen.

After unloading the specimens, a small region around the hole edge was cut and observed under an optical microscope in order to examine the failure initiating mechanisms (kink banding, microbuckling, fiber / matrix interface cracking, matrix cracking etc.). Both the in-plane and out-of-plane views of the failed region were examined and digital photomicrographs were next acquired.

\section{Results and Discussion}

\subsection{Room Temperature}

\subsubsection{Uniaxial Test}

Cross ply laminates show the typical kink banding failure mode (also identified before by a number of researchers, Ref. 1-12) at around a far field stress of $44 \mathrm{KSI}$. Failure initiates in the zero plies, at the hole edge, and propagates in a direction that is perpendicular to the direction of applied far-field load. Both inplane and out-ofplane kink banding occurs in the zero plies. In Figure 4, we show a typical view of the out-ofplane kink band. The surface strain at the hole edge in the direction of applied load at failure initiation is $7,500 \mu \varepsilon$ and the corresponding far field strain is approximately $3,000 \mu \varepsilon$.

The failure of the angle ply specimens subjected to the same type of loading is quite different. As indicated in Figure 5, the angle ply laminates when stressed in the $Y$-direction, fail by a mechanism of fiber matrix shearing. The failure is sudden so that the initiation and final failure occur almost at the same time. Because the strains near the hole edge are much larger than elsewhere, the failure initiates at the hole edge and traverses along the $60^{\circ}$ fiber angle (the crack runs through the matrix between the fibers). It appears that the $-60^{\circ}$ fibers running at an angle to 
the crack path do not provide the requisite crack bridging toughness to arrest the crack, so that once initiated the specimen is "split" cleanly along a line at $60^{\circ}$.

\subsubsection{Equibiaxial Test}

The main difference in response of the laminates between the uniaxial and the equibiaxial loading is not in the mechanism of failure but the magnitude of far-field loading necessary to achieve failure initiation. This was transpired by the measurements we performed. Thus, this shows that the mechanism of failure is intimately tied to the laminate lay-up and architecture, more so than the loading, for two cases we have examined so far.

For the case of cross ply laminates, since there are only $0^{\circ} / 90^{\circ}$ plies, failure initiation occurs by kink banding in the $0^{\circ}$ plies, starting from the hole edge at a position that is perpendicular to the direction of loading. Ideally, both kink bands (on either side of the hole) should happen at the same time, but due to material non-homogeneity or a slight perturbation of the symmetry of loading, one of the two kink bands form first, then followed by the other. The kink band formation leads to interlaminar cracking between the kinked ply and the adjacent $90^{\circ}$ ply (Figure 6$)^{5}$

\subsection{Elevated Temperature}

At elevated temperature, a new parameter emerges to influence the mechanism of failure. This parameter is associated with the shear-stress vs. shear strain response of the pure matrix behavior. Because of this, the laminate material properties are changed. Furthermore, due to the mismatch in the coefficients of thermal expansion, the nature of the fiber / matrix bond is also changed. In addition, the matrix rich region between plies which control the interlaminar strength is also affected.

As in the room temperature tests, failure initiation is sensed by a sudden increase in the through thickness (out of plane mode) strains, which allows the unloading of a specimen for postfailure microscopic examination of regions near the hole edge.

Cross ply laminates show extensive kink formation just as in the room temperature case.

\footnotetext{
${ }^{5}$ A summary of the measurements corresponding to the room temperature experiments are shown in Table 3.
}

Compared to the room temperature case, failure occurs at a lower load (See Table 4). Again, the kink banding initiates at the hole edge and propagates in a direction perpendicular to the direction of loading. Noticeably, the out of plane failure is very extensive. This observation may point to the reduced interlaminar strength on account of the elevated temperature, for the reasons discussed above. Figure 7 shows the appearance of the kink bands when viewed in the through the thickness direction.

In the case of the angle ply laminates, the maximum load drop is not as drastic as the cross ply laminates, but the maximum strain at the hole is reduced to about half when compared to the room temperature case. This shows that this particular mechanism of failure in angle ply laminates is not geometric, but rather it is controlled by a strength parameter. In this particular case, an examination of the failed specimens reveal that this strength parameter is the fiber / matrix interfacial strength.

\section{Concluding Remarks}

We have reported the experimental results of a series of uniaxial and equibiaxial inplane compressive loading experiments on notched composite laminated plates under room temperature and elevated temperature conditions. Two types of 48 ply graphite/epoxy composites were studied in order to understand their compressive failure mechanisms.

The laminate stacking sequence was selectively designed to bring out the different failure mechanisms that operate in angle plies and plies oriented in the loading direction. In specimens containing plies along the direction of the load (cross ply), uniaxial compression leads to fiber kink banding. This same scenario persists at both room and elevated temperature.

The angle ply specimens show failure along the fiber / matrix interface. The failure persists either at $+\theta$ or $-\theta$ angle or both. Fibers across the line of failure were broken due to the large amount of energy released as the interfacial crack propagates rapidly. At elevated temperature, the same failure mechanisms persist, but at different magnitudes of far-field loading.

\section{Acknowledgements}

We are grateful for financial support from the AFOSA under grant F49620-95-1-0326, and the 
Department of Aerospace Engineering at the University of Michigan.

\section{References}

1. Lekhnitskii S., Theory of Elasticity of an Anisotropic body, test, Godden-Day, 1968

2. Waas, A. M., and Schultheisz, C. R., 1995, "Compressive failure in Composites, Part II", Progress in Aerospace Science, Vol.32, pp. 43 -78 .

3. Starnes, J., Rhodes, M.D., and Williams, J.G., 1979, "Effect of Impact Damage and Holes on the Compressive Strength of a Graphite/Epoxy Laminate", Nondestructive Evaluation and Flaw Criticality for Composite Materials\}, edited by R. B. Pipes, ASTM STP 696, pp. 145-171.

4. Grape, J. and Gupta, V., 1995, Failure in Carbon / Polyamide Laminates under Biaxial Compression, J. Composite Materials, vol. 29, No. 14, pp1850-1872.]

5. Waas, A. and Bacock, C.D., Observation of the Initiation and Progression of Damage in Compressively loaded Composite Plates Containing a Cutout, GALCIT SM Report 8634(1986). See also GALCIT SM Report 85-12, by the same authors, 1985.\}

6. Waas, A., 1988, "Compression Failure of Fibrous Laminated Composites in the Presence of Stress Gradients: Experiment and Analysis", Ph.D. thesis, California Institute of Technology.

7. Waas, A.,Babcock, C.D. and Knauss, W.G. 1990, "An Experimental Study of the Compression Failure of Fibrous Laminated Composites in the Presence of Stress Gradients", International Journal of Solids and Structures, Vol. 26, No. 9/10, pp. 1071-1098.

8. Guynn, E. G., and Bradley, W. L., 1989, “A Detailed Investigation of the Micromechanisms of Compressive Failure in Open Hole Composite Laminates", Journal of Composite Materials, vol.23, May, pp.479-504.

9. Soutis, C., and Fleck, N.A., 1990, "Static Compression Failure of Carbon Fibre T800/924C Composite Plate with a Single Hole", Journal of Composite Materials, Vol. 24, pp. 536-558.

10. A. Khamseh and A. Waas, Failure Mechanisms in Uniply Composite Plates under Uniaxial Compression, ASME J. Materials and Technology, October, 1992.\}
11. A. Khamseh and A. Waas, Failure Mechanisms of Composite Plates with a Circular Hole under remote Biaxial Planar Compressive Loads, ASME J. Materials and Technology, vol. 119, pp56-64, 1997

12. Soutis, C., Fleck, N. and Smith, F., Failure Prediction Technique for Compression Loaded Carbon Fiber-Epoxy Laminate with an Open Hole, J. Composite Materials, 25, pp14761498, 1991

13. Soutis, C., Curtis, P. and Fleck, N., Compressive Failure of Notched Carbon Fiber Composites, Proc. Royal Soc. London A, 440, pp241-256, 1991.

14. Ahn, Junghyun, and Waas, Anthony, M., A Micromechanic-based finite element model for compressive failure of notched uniply composite laminates under remote biaxial load, ASME J. Eng. Materials \& Technology, 1999 (to Appear) 


\begin{tabular}{cccccc}
\hline Material & $\mathrm{E}_{11}$ (Msi) & $\mathrm{E}_{22}$ (Msi) & $\mathrm{G}_{12}$ (Msi) & $v_{12}$ & Thickness (in) \\
\hline $\begin{array}{c}\text { IM7 / 977-3 } \\
\text { epoxy }\end{array}$ & 23.5 & 1.21 & 0.72 & 0.3 & 0.0052 \\
\hline
\end{tabular}

Table 1 Zero ply material properties of the 48 ply graphite / 977- 3 epoxy composites

\begin{tabular}{cccccc}
\hline Laminate Type & Stacking Sequence & $\mathrm{E}_{\mathrm{xx}}(\mathrm{Msi})$ & $\mathrm{E}_{\mathrm{w}}(\mathrm{Msi})$ & $\mathrm{G}_{\mathrm{xy}}(\mathrm{Msi})$ & $v_{\mathrm{xy}}$ \\
\hline Quasi-isotropic & {$[+45 / 0 /-45 / 90]_{\infty \mathrm{c}}$} & 8.828 & 8.828 & 3.372 & 0.309 \\
Cross-Ply & {$[0 / 90]_{1 \mathrm{as}}$} & 12.401 & 12.404 & 0.7119 & 0.029 \\
Angle-Ply & {$[+60 /-60]_{123}$} & 1.492 & 7.383 & 4.698 & 0.309 \\
\hline
\end{tabular}

Table 2 Laminate material properties as determined from Classical Lamination Theory (CLT)

\begin{tabular}{|c|c|c|c|c|}
\hline $\begin{array}{c}\text { Specimen } \\
\text { Type }\end{array}$ & Loading Type & $\begin{array}{c}\text { Failure initiation load } \\
(\mathrm{Ksi})\end{array}$ & $\begin{array}{c}\text { Max. Hole Strain } \\
(\mu \varepsilon)\end{array}$ & Failure Mode \\
\hline Cross-Ply & Uniaxial & 44 & 7,500 & Kink at $0^{\circ}$ edge \\
\hline Cross-Ply & Biaxial & 37 & 6,600 & Kink in $0,90^{\circ}$ edge \\
\hline Angle-Ply & Uniaxial & 22.5 & 6,500 & Shear Failure $(+60 /-60)$ \\
\hline Angle-Ply & Biaxial & 35 & 4,500 & Shear Failure $(+60 /-60)$ \\
\hline
\end{tabular}

Table 3 Room Temperature (25 C $)$ Experimental Data

\begin{tabular}{|c|c|c|c|c|}
\hline $\begin{array}{c}\text { Specimen } \\
\text { Type }\end{array}$ & Loading Type & $\begin{array}{c}\text { Failure initiation load } \\
(\mathrm{Ksi})\end{array}$ & $\begin{array}{c}\text { Max. Hole Strain } \\
(\mu \varepsilon)\end{array}$ & Failure Mode \\
\hline Cross-Ply & Uniaxial & 19 & 2,700 & Kink at $0^{\circ}$ edge \\
\hline Cross-Ply & Biaxial & 18 & 2,080 & Kink in 0,90 edge \\
\hline Angle-Ply & Uniaxial & 22 & 3,284 & Shear Failure $(+60 /-60)$ \\
\hline Angle-Ply & Biaxial & 25 & 2,753 & Shear Failure $(+60 /-60)$ \\
\hline
\end{tabular}

Table 4 High Temperature $\left(200 \mathrm{C}^{\circ}\right.$ ) Experimental Data 


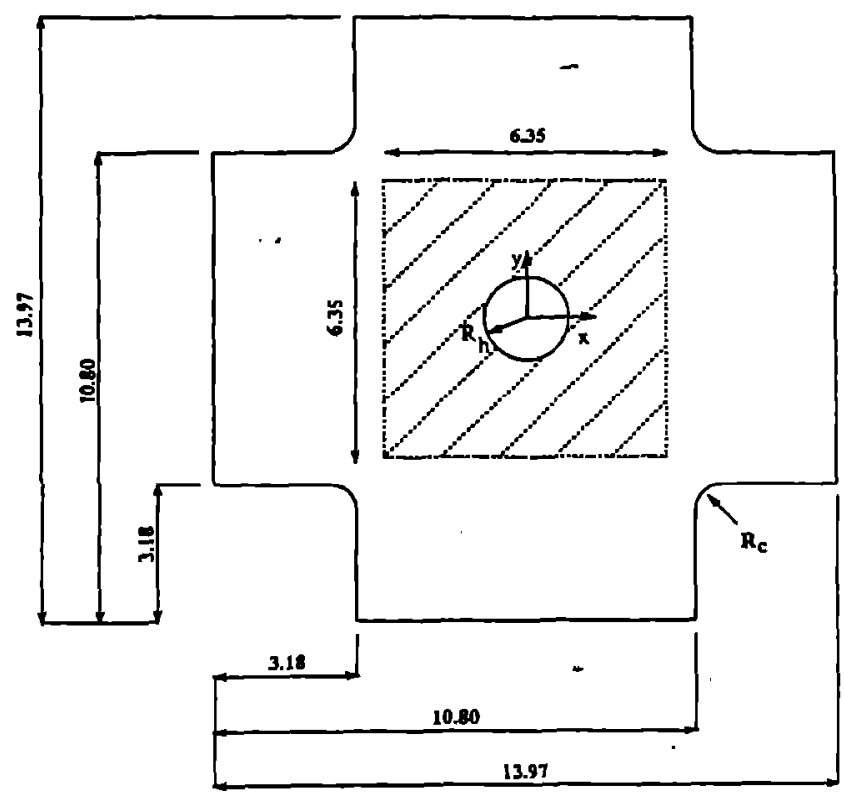

All dimensions are given in $\mathrm{cm}(+\$-0.127 \mathrm{~mm}$ tolerance)

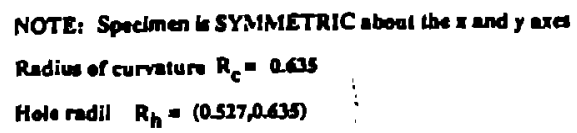

Figure 1 Specimen Geometry

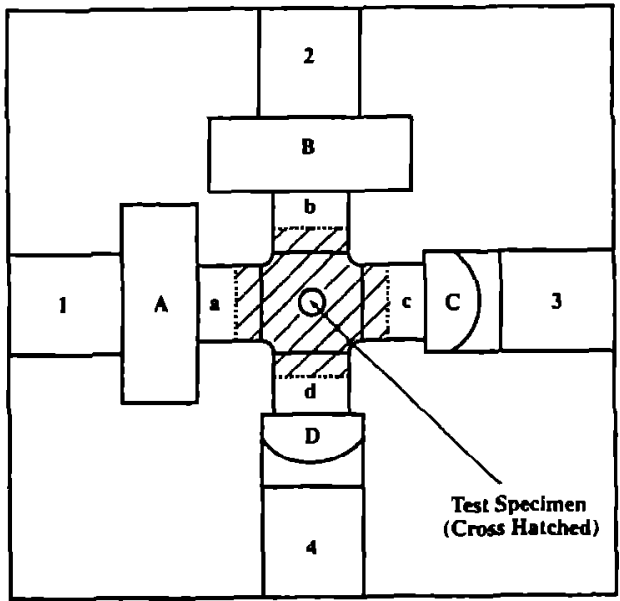

1,23,4 : Lerh. Top, Right, and Bottom hydraulic cylinders, respectively.

NOTE: Each cylinder can be driven with a load or displacement feedback, independant of the other three cylinders.

$A, B$ : Left and Top LoadCelly.

C,D : RJpht and Bottom Ball Jolnta, for spedmen allgmment.

a,b,c,d : Specimen firturea.

Figure 2 Schematics of working window in the biaxlal loading frame, deplcting the loading apparatus 


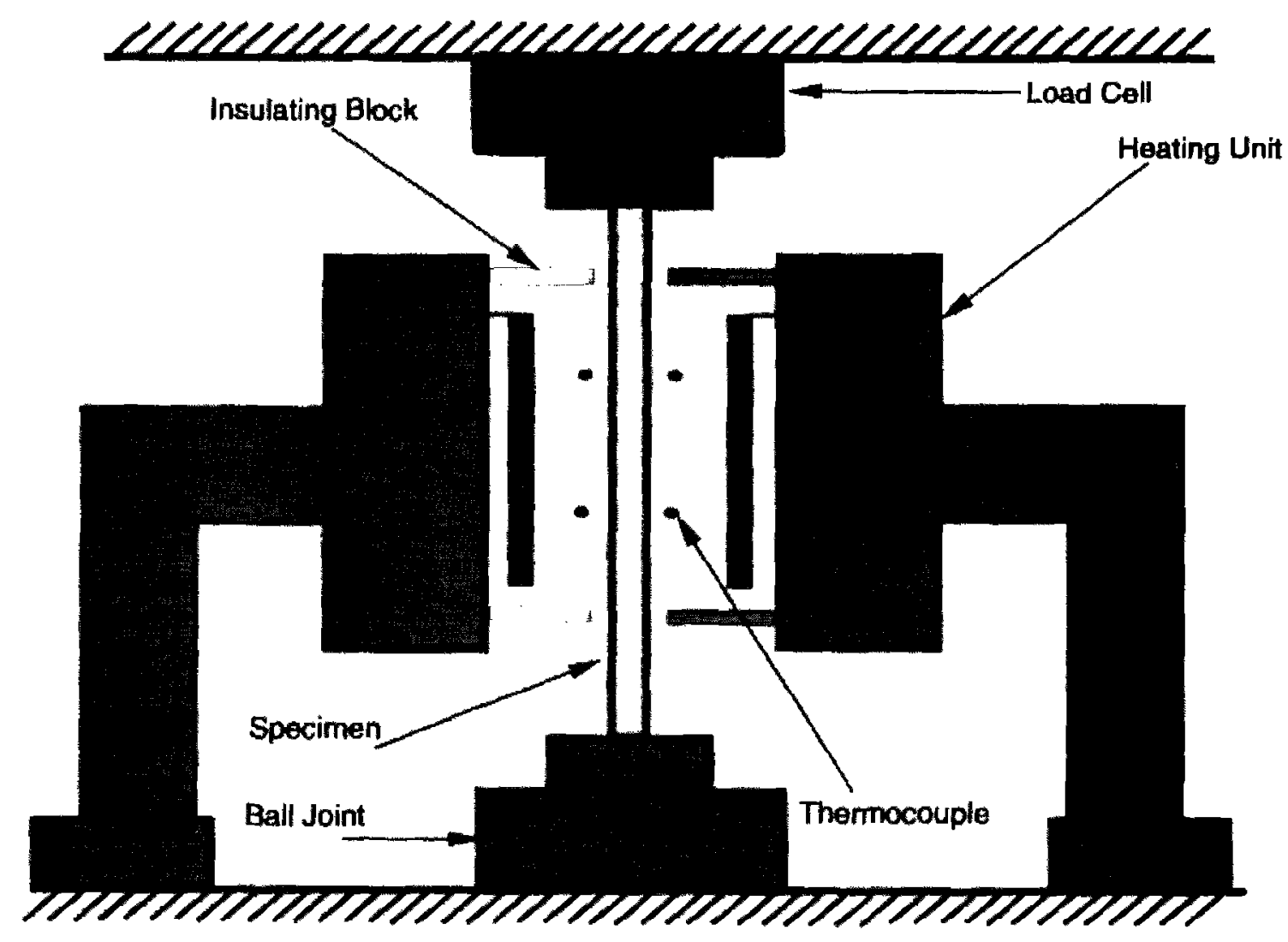

Figure 3 High temperature setup 


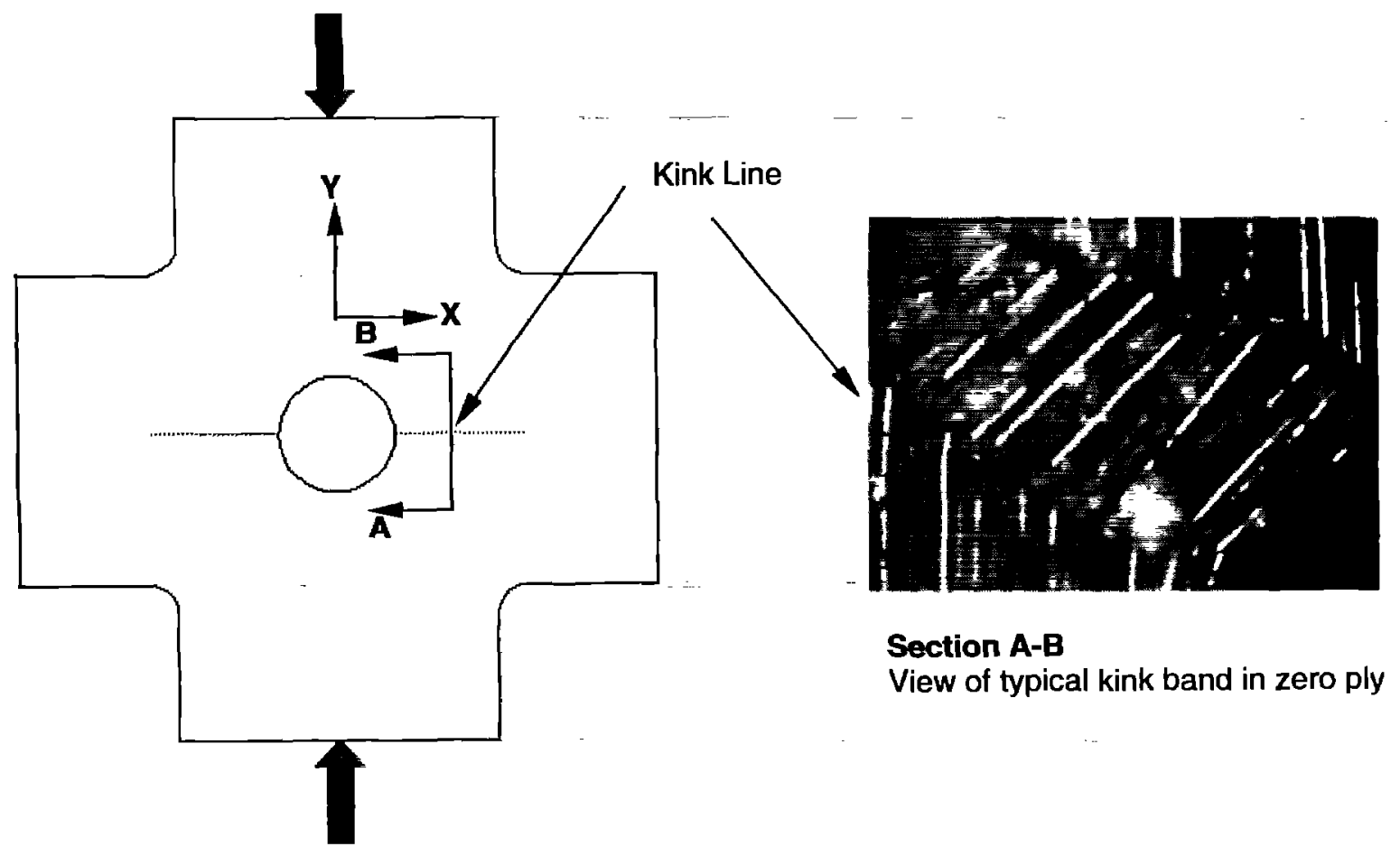

Figure 4 Cross Ply Laminates Failure Mechanism (Uniaxial)

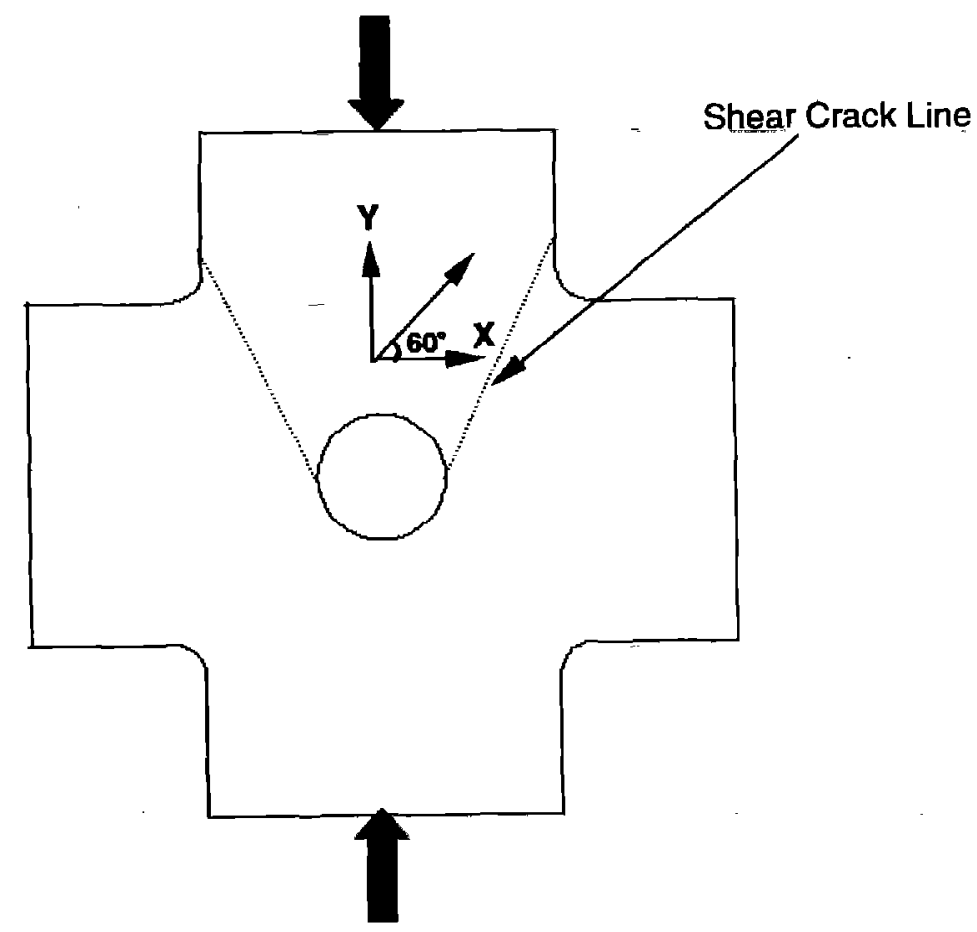

Figure 5. Angle-Ply Laminates Failure Mechanism (Uniaxial) 


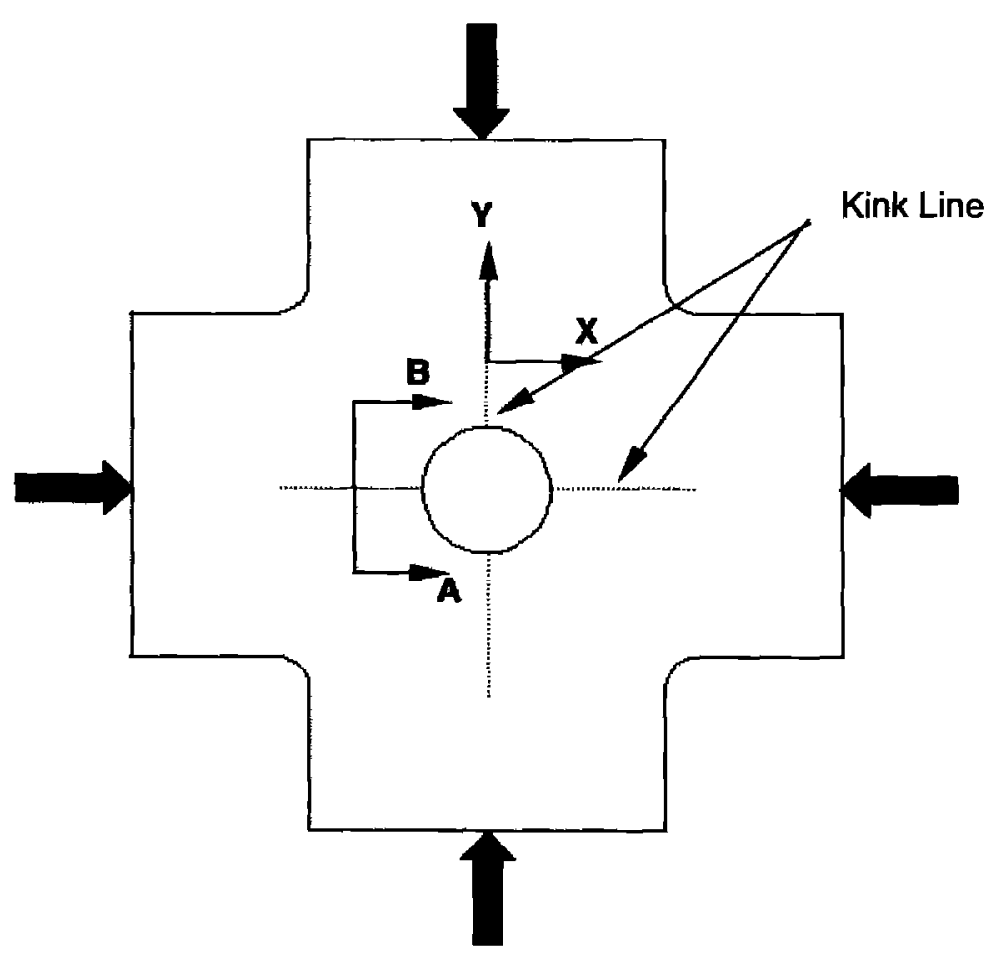

Figure 6. Cross-Ply Laminates Failure Mechanism (Biaxial)

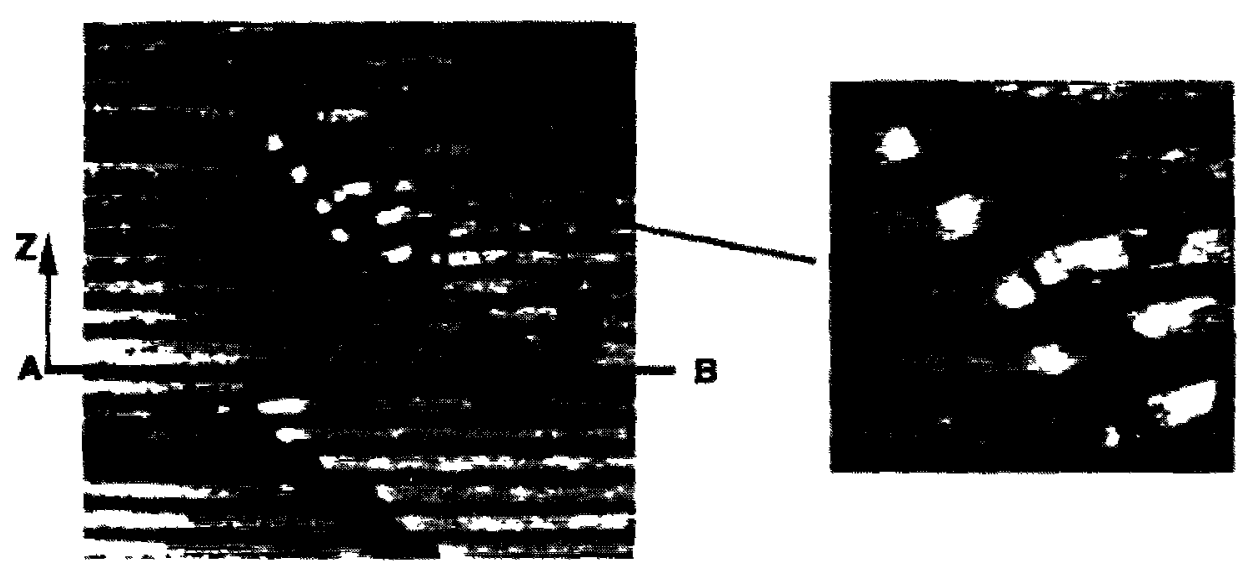

Figure 7. Cross-Ply Laminates Kink Formation Through Thickness 